\title{
Quality and Safety Analysis of 2,999 Telemedicine Encounters During the COVID-19 Pandemic
}

Charuta N. Joshi, MBBS, Michele L. Yang, MD, Krista Eschbach, MD, Suhong Tong, MS, Mona P. Jacobson, MSN, CPNP, Chelsey Stillman, PA-C, Annmarie E. Kropp, DNP, Stephanie A. Shea, BS, MPAS, PA-C, Gerard M. Frunzi, MBA, J. Fred Thomas, PhD, and Christina A. Olson, MD

Neurology: Clinical Practice April 2021 vol. 11 no. 2 e73-e82 doi:10.1212/CPJ.0000000000001025
Correspondence

Dr. Joshi

charuta.joshi@

childrenscolorado.org

\section{Abstract}

\section{Objective}

To examine whether telemedicine remains safe and of high quality despite rapid expansion of services by comparing telemedicine encounters before and during the COVID-19 pandemic.

\section{Methods}

Pre-post study investigating 2,999 telemedicine encounters: February 1, 2020-May 15, 2020, was performed. A total of 2,919 completed visits before and after strict social distancing implementation were analyzed for patient and provider characteristics, encounter characteristics (e.g., history and physical examination),

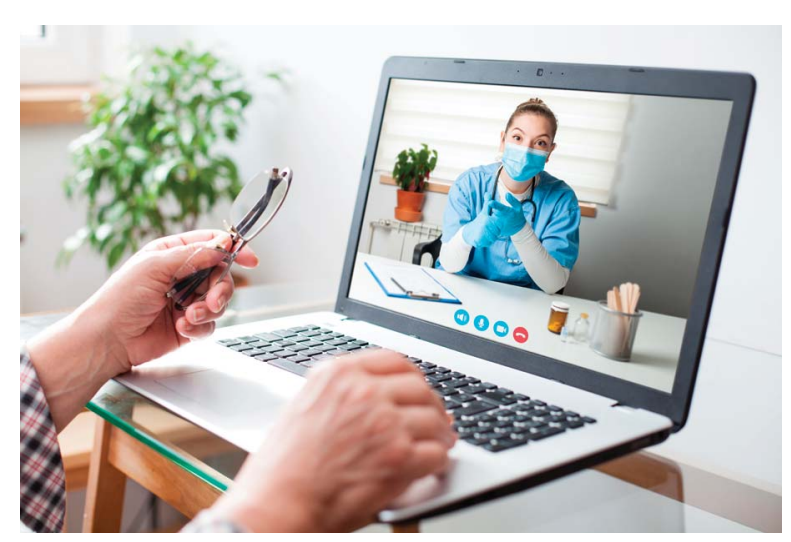
and quality and safety metrics (phone calls $\leq 7$ days postvisit, visit-cause-specific hospital admission or mortality $\leq 30$ days after visit). Stratified analysis of 3 groups for outcomes (young age, neuromuscular diagnosis, and new encounters) was performed.

\section{Results}

Patients ranging from 1 month to 33 years of age were seen. Rural patients were less likely to be seen during the pandemic compared with urban patients ( $8 \%$ vs $90 \%$; $p<0.0001$ ); teaching clinic and specialty clinic encounters increased significantly during the pandemic ( $8 \%$ vs $3 \% ; p=0.005)$, and documentation of at least 2 systems on examination was noted significantly more frequently during the pandemic ( $13 \%$ vs $7 \% ; p=0.009)$. No deaths were reported. There were no differences before/during the pandemic in safety or telemedicine failure metrics within the entire group and high-risk subgroups.

\section{Conclusions}

Despite a markedly and rapidly expanded scope of ambulatory telemedicine care during the COVID-19 pandemic, telemedicine remained a safe and high-quality option for pediatric neurology patients. In addition, populations perceived as high risk for telemedicine (the very young, new patients, and those with neuromuscular diagnoses) can benefit from telemedicine visits, particularly when access to in-person care is limited.

Telemedicine refers to a telecommunication-based remote evaluation of a patient and is a health care delivery method that improves access to care. ${ }^{1,2}$ In this article, telemedicine is more narrowly defined as live audio-visual evaluation of a patient.

Division of Pediatric Neurology (CNJ, MLY, KE, MPJ, CS, AEK, SAS), University of Colorado School of Medicine, Anschutz Medical Campus, Children's Hospital Colorado, Aurora; Department of Pediatrics (ST), Children's Hospital Colorado, Aurora; Department of Biostatistics and Informatics (ST), Colorado School of Public Health, University of Colorado School of Medicine, Anschutz Medical Campus, Aurora; Department of Pediatrics (JFT, CAO), University of Colorado School of Medicine, Anschutz Medical Campus, Children's Hospital Colorado, Aurora; and Telehealth Department (GMF, JFT, CAO), Children's Hospital Colorado, Aurora.

Funding information and disclosures are provided at the end of the article. Full disclosure form information provided by the authors is available with the full text of this article at Neurology.org/cp. 
Before the COVID-19 pandemic, the question was not "whether" telemedicine would become a part of routine patient care but "when," "where," and "how" it would. ${ }^{3-5}$

Despite barriers to implementation, ${ }^{1,5}$ pediatric neurology has adopted telemedicine at Children's Hospital Colorado predating the COVID pandemic. Outreach clinic-based telemedicine visits started in 2012; home-based telemedicine services for epilepsy, movement disorders, and neuropsychology started in 2018. However, before March 2020, telemedicine was limited to geographically remote areas, primarily for follow-up visits. For these clinics, patients traveled (generally a shorter distance) to a local hospital/clinic setting with telemedicine hosting capabilities (outreach location). Before the pandemic, any new patient encounters or encounters for patients who were very young and had primary neuromuscular symptoms were very limited because of perceived higher risk in seeing such patients via telemedicine.

We describe below our neurology-wide experience of nearly 3,000 home-based telemedicine encounters. We compare telemedicine visits performed 1 month before social distancing (BSD) with visits during strict social distancing (DSD) and analyze quality and safety balancing measures between them using a COVID-19-specific measurement framework developed by the Supporting Pediatric Research on Outcomes and Utilization of Telehealth (SPROUT) research network. ${ }^{6}$ We stratified analysis by age, diagnosis, and encounter type to evaluate metrics for success/failure of telemedicine visits.

\section{Methods}

\section{Standard Protocol Approvals, Registrations, and Patient Consents}

We conducted a pre-post study investigating telehealth use during the COVID-19 pandemic. We applied Strengthening the Reporting of Observational Studies in Epidemiology reporting standards. The Colorado Multiple Institutional Review Board deemed this research to be institutional review board exempt.

Retrospective, manual chart review was performed for all telemedicine encounters in pediatric neurology between February 1 and May 15 using electronic medical record (EMR) key terms to identify telemedicine visits in pediatric neurology. The chart review was performed by pediatric neurology physicians and nurse practitioners spanning multiple subspecialties and by the telemedicine program's medical director. Demographic review was performed by members of the telemedicine team.

\section{Time Frame for Analysis February 1, 2020-May 15, 2020}

February (February 1, 2020-February 28, 2020) served as a baseline month before the implementation of social distancing. Analysis ended on May 15 because outpatient clinics reopened for nonurgent visits on May 11. Another automated EMR data extraction was performed from May 15,2020 , to June 1,2020 , to see the effect of clinic reopening on telemedicine encounter volume $(n=614)$, but these encounters were not individually/manually analyzed.

\section{Search Terms}

Using the above time frame and our EMR (EPIC), we extracted all outpatient pediatric neurology encounters using the search terms NEUROLOGY, NEUROPSYCHOLOGY at 2 primary ambulatory sites that represent $75 \%$ of our providers.

\section{Statistical Analysis}

Categorical variables were described as proportions or percentages with $95 \%$ confidence intervals. The $\chi^{2}$ test was performed to compare the differences in proportions for overall tests of significance and for pairwise comparisons for the levels of the variables when the overall test was significant. $p<0.05$ was used to denote statistical significance. SASV9.4 and GraphPad Prism V8.3 were used for all analyses.

Variables used to study these visits are described in detail in table 1 and were broadly divided into patient variables (e.g., age and location), clinic/provider variables (e.g., physician/ advanced practice provider, teaching clinic, and multidisciplinary clinic), examination variables (vital signs and number of systems examined), assessment/plan variables (e.g., diagnosis, controlled substances prescribed, and new referral made), counseling-related topics (e.g., review of results), and balancing quality and safety metrics (documentation of video failure, phone call $\leq 7$ days of telemedicine visit, and visit-causespecific hospitalization/death $\leq 30$ days).

\section{The Following Definitions and Categories Were Used to Identify These Variables During Data Review Completed Visit}

An encounter was considered completed if there was documentation that a live audio-visual encounter occurred. If there was any technical problem during the visit that needed a telephone call-but it occurred after a necessary and suffcient examination could be performed, the visit was classified as a completed visit with a technical failure noted.

\section{Incomplete Visit}

An encounter was considered an incomplete visit if the visit was canceled, rescheduled, patient did not show, audio-visual visit could not be initiated up to the day and time of the encounter, or the visit started, and the clinician converted part/entire encounter to telephone before completing a necessary and sufficient examination.

\section{Teaching Clinic Visit}

Visits performed in conjunction with residents/fellows.

\section{Multidisciplinary Clinic}

Visits in which multiple providers used a single EMR encounter to see a patient. 
Table 1 Variables Analyzed in This Article: Quality and Balancing Metrics Used Were Adapted From the Supporting Pediatric Research on Outcomes and Utilization of Telehealth Guidelines

\begin{tabular}{|c|c|c|}
\hline Variable: overarching outline & Specific variable abstracted from visit & Further variable details as applicable \\
\hline \multirow[t]{5}{*}{ Patient demographics } & Primary insurance type & Commercial/Medicaid/Tricare/other \\
\hline & $\begin{array}{l}\text { Distance from patient location to provider } \\
\text { location }\end{array}$ & $<50 \mathrm{mi}, 50-100 \mathrm{mi}$, and $>100 \mathrm{mi}$ \\
\hline & Home location type & Urban/rural/frontier \\
\hline & State of residence & Co/other \\
\hline & Patient new to neuro & Yes/no \\
\hline \multirow[t]{6}{*}{ Clinic/provider demographics } & $\begin{array}{l}\text { Patient location type at the time of telemed } \\
\text { encounter }\end{array}$ & Outreach clinic/satellite hospital/home \\
\hline & Multidisciplinary clinic encounter & Yes/no \\
\hline & Teaching clinic encounter & With residents/fellows \\
\hline & Research encounter & Visit for clinical research \\
\hline & Primary provider type & MD/APP/RD/RN \\
\hline & Primary provider specialty & $\begin{array}{l}\text { General, movement disorder, epilepsy, } \\
\text { stroke, and keto diet }\end{array}$ \\
\hline \multirow[t]{2}{*}{ Examination } & Any vitals & HR/RR/weight/pain score \\
\hline & Describe the number of systems examined & $\begin{array}{l}\text { Only neuro examination, general assessment } \\
+ \text { neuro examination, and examination } \\
\text { covering more systems than general + neuro }\end{array}$ \\
\hline \multirow[t]{6}{*}{ Assessment/plan } & New diagnosis made & Yes/no \\
\hline & Plan made in visit & $\begin{array}{l}\text { Continue previous plan/reassurance, new } \\
\text { test ordered, and new meds prescribed }\end{array}$ \\
\hline & New referral generated & Yes/no \\
\hline & $\begin{array}{l}\text { Close follow-up recommended (generally if }< \\
3 \mathrm{mo} \text { ) }\end{array}$ & $\begin{array}{l}\text { Note also if closer than recommended for } \\
\text { provider and diagnosis type }\end{array}$ \\
\hline & Was a new controlled substance prescribed & Yes/no \\
\hline & Was a controlled substance refilled & Yes/no \\
\hline \multirow[t]{4}{*}{ Counseling } & Review of results & Yes/no \\
\hline & Discussion of new or existing diagnosis & Yes/no \\
\hline & Risks/benefits of treatment plan & Yes/no \\
\hline & Anticipatory guidance & $\begin{array}{l}\text { New meds in future, water safety, transition, } \\
\text { pregnancy, and vaccines }\end{array}$ \\
\hline \multirow[t]{4}{*}{$\begin{array}{l}\text { Quality and balancing metrics for } \\
\text { telemedicine }\end{array}$} & Failure of telemedicine & $\begin{array}{l}\text { Documentation that the video visit was } \\
\text { converted to phone in total or midway } \\
\text { through visit, patient not present when they } \\
\text { needed to be there, unable to get language } \\
\text { interpretation for the video visit, and } \\
\text { regulatory issue }\end{array}$ \\
\hline & Patient called the clinic within $7 \mathrm{~d}$ of the visit & $\begin{array}{l}\text { Need for clarification of plan established } \\
\text { during visit or to discuss an incomplete item }\end{array}$ \\
\hline & $\begin{array}{l}\text { Patient seen in-person within } 30 \mathrm{~d} \text { of the } \\
\text { telemed visit for the same symptom/ } \\
\text { diagnosis }\end{array}$ & $\begin{array}{l}\text { Need for further in-person examination or } \\
\text { workup identified during the telemed visit, } \\
\text { disease severity/complexity requiring in- } \\
\text { person care, patient/family desired in-person } \\
\text { care but not required per provider, and other } \\
\text { reason for in-person care }\end{array}$ \\
\hline & $\begin{array}{l}\text { Admitted to the hospital within } 7 \mathrm{~d} \text { of the } \\
\text { telemed visit for the same symptom/ } \\
\text { diagnosis }\end{array}$ & Yes/no \\
\hline
\end{tabular}


Table 1 Variables Analyzed in This Article: Quality and Balancing Metrics Used Were Adapted From the Supporting Pediatric Research on Outcomes and Utilization of Telehealth Guidelines (continued)

\begin{tabular}{lll}
\hline Variable: overarching outline & Specific variable abstracted from visit & Further variable details as applicable \\
\hline & $\begin{array}{l}\text { Admitted to hospital within 8-30 d of telemed } \\
\text { visit for the same symptom/diagnosis }\end{array}$ & Yes/no \\
\hline Diagnosis & $\begin{array}{l}\text { Unanticipated death within } 30 \mathrm{~d} \text { of telemed } \\
\text { visit }\end{array}$ & Yes/no \\
\hline
\end{tabular}

\section{BSD and DSD}

Visits during February 1, 2020-February 28, 2020 (baseline month), and May 11, 2020-May 15, 2020 (1 week after clinics reopened), were considered to be BSD visits. Visits during March 1, 2020-May 11, 2020, were considered to be DSD.

\section{Distance From in-Person Care Calculation}

This was calculated using 2 zip codes: provider's primary practice location and the patient's residence.

\section{Urban/Rural/Frontier Location}

An urban area has a population of 50,000; any area that is not urban is considered rural, whereas a frontier location has a population of $\leq 6$ per square mile. Any area not considered urban or frontier is classified as rural.

\section{Comparison by Age}

Patients were divided into 3 groups: $<24$ months, 24-60 months, and $>60$ months and compared for all variables.

\section{Comparison by Encounter Type}

New referrals were compared against follow-up neurology visits.

\section{Comparison by Diagnosis}

When multiple diagnoses were coded, the primary diagnosis was assigned by cross-checking the chief complaint and assessment section of the telemedicine encounter note. Patients with a diagnosis of neuromuscular disorder were compared with patients with epilepsy for all variables.

\section{Telemedicine Service Description}

During prepandemic in-person clinic operations, 80-100 outpatient pediatric neurology visits occurred per day for multiple chief complaints. Care is provided by a team of 60 physicians, advanced practice providers, and neuropsychologists. Nurses provide teaching for rescue therapies in seizure disorders.

Starting on March 6, 2020, physicians were asked to move patients already scheduled in their in-person clinics to telemedicine appointments. If for any reason the physician thought that it is necessary to see an upcoming patient in person, that was respected and those patients were not seen through telemedicine. Telemedicine encounters were performed via a HIPAA-compliant video-conferencing platform (Vidyo) launched through the EMR-based patient portal and the provider's EMR clinic schedule. To facilitate rapid expansion, all upcoming patients were advised to activate their patient portal account and download the Vidyo software driver or mobile application to their device. A good internet connection and/or cellular data were a prerequisite to achieve successful home-based visits, and both the provider and patient needed access to a computer with a webcam, a tablet, or a smartphone.

To prepare for the telemedicine encounter, clinic coordinators sent a patient portal message 1 week before the appointment explaining regulatory requirements such as consent and need for the patient's presence and then initiated a phone call 30 minutes before the appointment to address technical concerns, do medication reconciliation, obtain vital signs as available (every patient was asked to get a weight on a home scale if available or estimate weight change since the last in-person encounter in our system if no scale was available), and ask whether forms such as an updated seizure action plan were needed. Physicians were responsible for medication reconciliation, refills, and other needs of the patient if the preparatory call did not cover these steps. We did not use telemedicine-specific templates in our EMR.

Table 3 and supplementary figure e-1 (links.lww.com/CPJ/ A235) describe the timeline and steps implemented in operationalizing clinic flow to optimize telemedicine visits.

\section{Data Availability}

Anonymized data not published within this article will be made available by request from any qualified investigator.

\section{Results}

Table 2 describes salient features of data BSD and DSD. Raw data are available in supplementary tables (tables e-1-e-4, links.lww.com/CPJ/A236, links.lww.com/CPJ/A237, links. lww.com/CPJ/A238, and links.lww.com/CPJ/A239).

Between February 1 and May 15, a total of 2,999 telemedicine encounters were identified. Because qualitative examination 
Table 2 BSD and DSD Table With Salient Data

\begin{tabular}{|c|c|c|c|c|c|c|c|}
\hline Variable & Overall & $\begin{array}{l}\text { February 1-28 } \\
\text { and May } \\
11-15 \text { BSD }\end{array}$ & $\begin{array}{l}\text { March 1-May } \\
10 \text { DSD }\end{array}$ & $\begin{array}{l}\text { Overall } \\
p \text { values }\end{array}$ & $\begin{array}{l}\text { Pairwise } \\
p \text { values }\end{array}$ & $\begin{array}{l}\text { February 1-28 } \\
\text { and May 11-15 } \\
\text { (LCL-UCL) }\end{array}$ & $\begin{array}{l}\text { March 1-May } \\
10 \text { (LCL-UCL) }\end{array}$ \\
\hline Age groups, y & & & & 0.5649 & & & \\
\hline$<2$ & $159(7.51 \%)$ & $13(5.75 \%)$ & $146(7.72 \%)$ & & & & \\
\hline $2-5$ & $245(11.57 \%)$ & $26(11.50 \%)$ & $219(11.58 \%)$ & & & & \\
\hline$>5$ & $1714(80.93 \%)$ & $187(82.74 \%)$ & $1527(80.71 \%)$ & & & & \\
\hline $\begin{array}{l}\text { Distance from the patient's home } \\
\text { to the provider's primary practice } \\
\text { location in miles }\end{array}$ & & & & $<0.0001$ & & & \\
\hline$<50$ & $1,550(75.32 \%)$ & $140(63.06 \%)$ & $\begin{array}{l}1,410 \\
(76.80 \%)\end{array}$ & & $<0.0001$ & $56.71 \%-69.41 \%$ & $74.87 \%-78.73 \%$ \\
\hline $50-100$ & $244(11.86 \%)$ & $23(10.36 \%)$ & $221(12.04 \%)$ & & 0.4654 & & \\
\hline$>100$ & $264(12.83 \%)$ & $59(26.58 \%)$ & $205(11.17 \%)$ & & $<0.0001$ & $20.77 \%-32.39 \%$ & $9.72 \%-12.61 \%$ \\
\hline Primary provider specialty & & & & 0.0108 & & & \\
\hline General clinic & $1,003(47.33 \%)$ & $131(57.96 \%)$ & $872(46.06 \%)$ & & 0.0007 & $51.53 \%-64.40 \%$ & $43.82 \%-48.31 \%$ \\
\hline Movement disorder & $114(5.38 \%)$ & $6(2.65 \%)$ & $108(5.71 \%)$ & & 0.0547 & $0.56 \%-4.75 \%$ & $4.66 \%-6.75 \%$ \\
\hline Headache & $285(13.45 \%)$ & $18(7.96 \%)$ & $267(14.10 \%)$ & & 0.0106 & $4.43 \%-11.49 \%$ & $12.54 \%-15.67 \%$ \\
\hline Any vitals & & & & $<0.0001$ & & & \\
\hline Yes & $1,509(71.21 \%)$ & $201(88.94 \%)$ & $\begin{array}{l}1,308 \\
(69.10 \%)\end{array}$ & & & $84.85 \%-93.03 \%$ & $67.02 \%-71.18 \%$ \\
\hline Plan made in visit & & & & 0.0005 & & & \\
\hline New meds prescribed & $603(28.46 \%)$ & $52(23.01 \%)$ & $551(29.11 \%)$ & & 0.0548 & $17.52 \%-28.50 \%$ & $27.06 \%-31.15 \%$ \\
\hline New test/procedure ordered & $479(22.61 \%)$ & $42(18.58 \%)$ & 437 (23.09\%) & & 0.1263 & $13.51 \%-23.66 \%$ & $21.19 \%-24.98 \%$ \\
\hline $\begin{array}{l}\text { New meds + new test/procedure } \\
\text { ordered }\end{array}$ & $279(13.17 \%)$ & $50(22.12 \%)$ & $229(12.10 \%)$ & $<0.0001$ & & $16.71 \%-27.54 \%$ & $10.63 \%-13.57 \%$ \\
\hline Admitted to hospital within $7 \mathrm{~d}$ & & & & 0.8552 & & & \\
\hline Yes & $14(0.66 \%)$ & $2(0.88 \%)$ & $12(0.63 \%)$ & & & & \\
\hline Admitted to hospital within $8-30 \mathrm{~d}$ & & & & 0.2930 & & & \\
\hline Yes & $16(0.76 \%)$ & $3(1.33 \%)$ & $13(0.69 \%)$ & & & & \\
\hline Diagnosis type & & & & 0.0008 & & & \\
\hline Headache/migraine & $594(28.05 \%)$ & $55(24.34 \%)$ & $539(28.49 \%)$ & & 0.1891 & & \\
\hline Seizure/spells & $222(10.48 \%)$ & $37(16.37 \%)$ & $185(9.78 \%)$ & & 0.0022 & $11.55 \%-21.20 \%$ & $8.44 \%-11.12 \%$ \\
\hline Syncope & $15(0.71 \%)$ & $1(0.44 \%)$ & $14(0.74 \%)$ & & 0.6142 & & \\
\hline Movement disorder & $161(7.60 \%)$ & $11(4.87 \%)$ & $150(7.93 \%)$ & & 0.1008 & & \\
\hline Epilepsy & 845 (39.90\%) & $107(47.35 \%)$ & $738(39.01 \%)$ & & 0.0155 & $40.84 \%-53.85 \%$ & $36.81 \%-41.20 \%$ \\
\hline Neuromuscular & $74(3.49 \%)$ & $4(1.77 \%)$ & $70(3.70 \%)$ & & 0.1354 & & \\
\hline Neuroimmune & $19(0.90 \%)$ & $0(0.00 \%)$ & $19(1.00 \%)$ & & 0.1302 & & \\
\hline Developmental delay & $54(2.55 \%)$ & $1(0.44 \%)$ & $53(2.80 \%)$ & & 0.0335 & $0.00 \%-1.31 \%$ & $2.06 \%-3.54 \%$ \\
\hline Stroke & $3(0.14 \%)$ & $1(0.44 \%)$ & $2(0.11 \%)$ & & 0.2033 & & \\
\hline Other & 131 (6.19\%) & 9 (3.98\%) & 122 (6.45\%) & & 0.1458 & & \\
\hline
\end{tabular}

Abbreviations: $B S D=$ before social distancing; DSD = during strict social distancing; $L C L=$ lower confidence level; $U C L=$ upper confidence level. 95\% confidence interval-LCL to UCL. 
of variables used for a neurology clinical visit could not be used for a neuropsychology visit or a nurse visit, they were excluded from further analysis.

After eliminating canceled/rescheduled/no show visits $(\mathrm{n}=$ $576)$, incomplete visits $(n=36)$, nurse visits $(n=27)$, and neuropsychology visits $(\mathrm{n}=241), 2,119$ completed clinician visits were included for final analysis.

\section{Overall Descriptors of the Cohort}

The youngest patient seen was 1 month old, and the oldest was 33 years old (median 11.5 years; interquartile range 6.4-15.4 years). Highest daily completed visit volume of 96 occurred on April 20. Only 7.5\% (159/2,119) encounters were for patients less than 24 months of age. Seventy-five percent of the patients lived within 50 miles of the hospital in an urban area. Ninety-eight percent of the patients were in their homes, in Colorado (97\%), and were seen for follow-up (62\%). Overall, $71 \%$ had documentation of $>2$ systems examined, whereas $9.4 \%$ had only a neurology examination, and $7.5 \%$ had no examination documented. Overall, only $0.7 \%(\mathrm{n}=14)$ were admitted to the hospital $\leq 7$ days after the visit, and $0.8 \%(\mathrm{n}=16)$ were admitted between days 8 and 30. No deaths occurred within 30 days of a telemedicine visit. Figure 1 shows weekly numbers of visits.

\section{Comparison of Visits BSD and DSD}

BSD and DSD groups did not differ with respect to insurance type, patients age, state of residence (Colorado vs neighboring states), type of visit (new or follow-up), provider type (physician vs advanced practice provider), or clinic type (multidisciplinary vs non-multidisciplinary).

In addition, the frequency of not documenting a neurology examination, making a new diagnosis, generating a referral,

Figure 1 Weekly Numbers of Telemedicine Visits Starting February 1 Through June 1, 2020

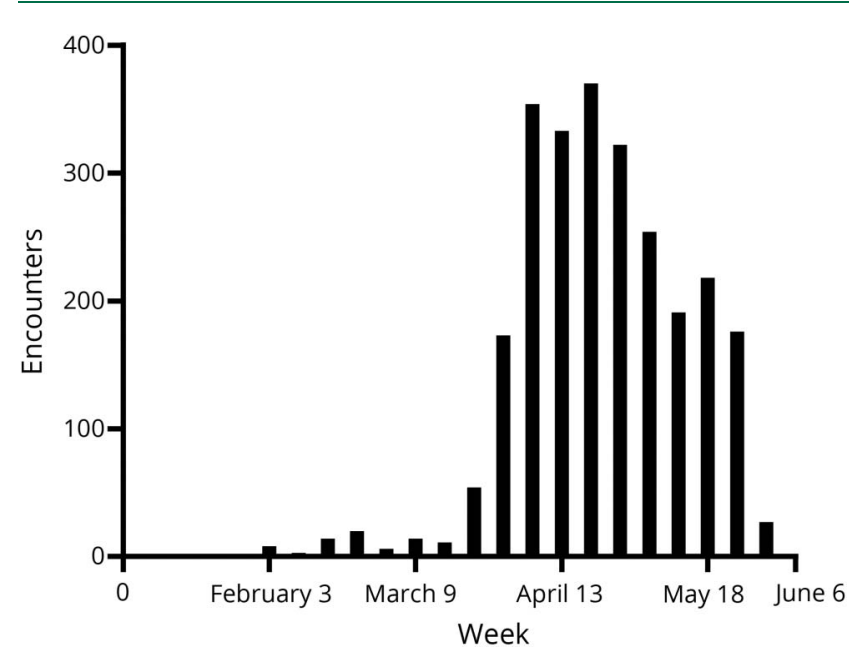

and newly prescribing or refilling a controlled substance were equally likely BSD vs DSD. Rates of telemedicine failure (per metrics in table 1) were no different BSD and DSD, and patients were equally likely to be admitted to the hospital within 7 days and within 8-30 days BSD or DSD.

The 2 groups differed significantly BSD vs DSD, respectively, for several patient demographics: more patients were within 50 miles (63\% vs $77 \%$; $p<0.0001)$; less patients were $>100$ mile ( $27 \%$ vs $11 \%$; $p<0.0001)$; rural patients were less frequently seen than urban patients DSD (7.8\% vs $90 \%$; $p<$ $0.0001)$; and more patients were seen in their home than at an outreach clinic ( $87 \%$ vs $99 \% ; p<0.0001$ ). Both teaching clinic and headache clinic telemedicine use increased significantly DSD ( $3 \%$ vs $8 \% ; p=0.005$, and $8 \%$ vs $14 \% ; p=$ 0.011 , respectively).

During the encounter itself, vitals and a general + neurology system examination were documented more frequently DSD than BSD ( $89 \%$ vs $69 \%$; $p<0.0001$, and $12.6 \%$ vs $6.6 \%$; $p=$ 0.009 , respectively). Risks and benefits of treatment were documented less frequently DSD ( $96 \%$ vs $89 \%$; $p=0.001$ ). Of interest, anticipatory guidance was documented more clearly BSD than DSD ( $87 \%$ vs $79 \% ; p=0.003$ ). Closer follow-up was recommended DSD, but this did not reach statistical significance $(17 \%$ vs $12 \% ; p=0.051)$.

\section{Failure of Telemedicine Measures in Completed Visits}

Of the $50(2.3 \%)$ patients who were seen again for an inperson visit within 30 days of a telemedicine visit, 32 were seen because of the need for an in-person examination (no difference BSD vs DSD). Fourteen were seen because of medical complexity of the patient. Of these 14, significantly less were seen DSD than BSD ( $0.5 \%$ vs $1.8 \%, p=0.029)$. Video encounters were converted to a phone visit during the visit only $1 \%$ of the time, and phone calls to the clinic within 7 days for the same complaint were $<9 \%$.

\section{No Show/Canceled Visits-Incomplete Visits}

Five hundred seventy-six patients canceled or did not show, and 36 visits were incomplete $(n=612 ; 20 \%)$. Of those, 49 ( $8 \%$ ) converted to a phone encounter because of connectivity/IT issues, 66 (10.8\%) were canceled as the patient was unavailable, and 221 (36\%) were rescheduled. Two hundred forty-one (39\%) canceled without a reason documented in chart, and 31 (5\%) did not show to the visit. There were no cancellations documented because of issues with interpreters and 2 canceled because of regulatory (consent, licensure, and insurance) issues. Two were later found to be valid visits.

\section{Analysis of Specific Groups Within the Entire Telemedicine Cohort Analysis by Age}

Compared with patients $>60$ months, patients $<24$ months were more likely to be new referrals (63\% vs $35 \%$; $p<0.0001$ ). 
There was a greater likelihood of a new diagnosis (49\% vs 28\%; $p<0.0001)$ and recommendations for a closer follow-up (27\% vs $16 \% ; p=0.002$ ). A general plus neuro examination was more likely completed ( $29 \%$ vs $10 \%$; $p<0.0001$ ). Less counseling was documented in younger patients $(73 \%$ vs $92 \%$; $p<$ 0.0001 ). Younger patients called more frequently within 7 days of the visit $(13.8 \%$ vs $7.5 \%$; $p=0.001)$.

\section{Analysis by Diagnosis}

We compared patients who had a diagnosis of neuromuscular disorders against patients with a diagnosis of epilepsy. Patients with a neuromuscular diagnosis were more likely to be younger than 24 months ( $15 \%$ vs $5 \% ; p=0.002$ ); vitals were more likely to be documented for a patient with epilepsy than a neuromuscular diagnosis ( $74 \%$ vs $53 \%$; $p=$ 0.0001 ). A new diagnosis was less commonly made for patients with epilepsy ( $9 \%$ vs $22 \%$; $p<0.0001$ ), but medications were more commonly prescribed $(25 \%$ vs $11 \% ; p=0.001)$. New referrals were made more commonly in patients with a neuromuscular diagnosis (27\% vs $12 \%$; $p$ $=0.0002)$ and closer follow-up recommended ( $27 \%$ vs $8 \%$; $p<0.0001)$. There was no difference between prescriptions for controlled substances between the 2 groups. Patients with epilepsy were significantly more likely to call within 1 week ( $9 \%$ vs $1 \% ; p=0.027$ ).

\section{Comparison of New vs Follow-up Visits}

New patient visits were more likely in patients younger than 5 years $(13 \%$ vs $4 \% ; p<0.0001)$. There was greater documentation of vital signs ( $77 \%$ vs $68 \%$; $p<0.0001$ ) and more systems were examined compared with follow-up patients $(16 \%$ vs $10 \% ; p<0.001)$. Although new patients were more likely to call the clinic within 7 days of the visit compared with follow-up patients ( $11 \%$ vs $7 \% ; p=0.0001)$, there were no differences in the rate of in-person examinations or hospital admissions after telemedicine visit between the 2 groups.

\section{Discussion}

Necessity is the mother of invention. For telemedicine, during the COVID-19 pandemic, necessity was the mother of implementation. During the first week of March, an increasing number of COVID-19-positive patients were identified in Colorado, with the Governor shortly thereafter issuing social distancing requirements and, later, stay-at-home orders. In the 2nd week of March, access to nonurgent, outpatient care became lawfully restricted for every patient, irrespective of their geographic location, payor status, or ability to travel. Therefore, telemedicine to patients' homes rapidly became the predominant means of providing care to patients.

Irrespective of any inherent biases for or against telemedicine or our perceptions about barriers to telemedicine, we adapted during this time by increasing our telemedicine capabilities to all nonurgent patients, increasing information technology support to physicians, and coaching physicians on how to "examine patients during a telemedicine visit." By the third week of April, we were seeing close to $75 \%$ of patients virtually as we saw in person pre-COVID-19 (see figure 1 for weekly totals counted each Monday).

In this pre-post study using retrospective chart review of 2119 pediatric telemedicine visits, our aim was not to analyze patient/provider satisfaction or telemedicine feasibility. We wished to analyze variables that could contribute to successes and failures and quality and safety of this unprecedented rapid implementation of outpatient telemedicine in pediatric neurology. Ours is the first study that uses this methodology. Overall, our study indicates that rapid unplanned expansion of telemedicine in response to pandemic-related social distancing did not result in a degradation of care and that telemedicine was appropriate for a much larger scope of patient care than previously thought in our practice.

Being early adopters of telemedicine in pediatric neurology explains why our BSD and DSD groups did not differ much when comparing many patient demographic and provider characteristic variables.

However, prepandemic, mainly outreach clinic-based telemedicine visits restricted to epilepsy and movement disorder follow-up meant that the scope of care (particularly for diagnoses needing complex or multidisciplinary clinics) was limited until social distancing changed our practice model. The finding of a statistically significant increase in the number of home-based visits, certain specialty clinics, and teaching clinics DSD was therefore expected.

The high number of urban rather than rural patients DSD likely reflects 3 factors: closure of outreach telemedicine clinics in rural areas DSD, internet limitations/device availability that made home-based telemedicine more difficult for rural patients, and large numbers of urban patients near our clinics who primarily used in-person care BSD.

Telemedicine is supposed to eliminate socioeconomic boundaries to access; however, this discrepancy in the home-based vs outreach clinic-based visits that occurred DSD is uniquely related to patient demographics and has been noted in another recent article. ${ }^{7}$ Having access to broadband internet and knowledge about the use of technology during COVID-19 have become determinants of health outcomes as also noted by others. ${ }^{8,9}$

There was a significant increase in the documentation of vital signs and number of systems evaluated during the physical examination, DSD compared with BSD. This was likely multifactorialincreasing knowledge about telemedicine practice with time, higher provider acceptance, new targeted coaching and education for providers as noted in table 3 , figure e-4, and the proliferation of resources to support neurologic examination. ${ }^{10-12}$

One explanation for tendency toward recommending closer follow-up DSD could be a perception by providers newer to telemedicine that a telemedicine visit was incomplete and 
Table 3 Timeline and Steps Taken to Rapidly Expand Telemedicine Services

\begin{tabular}{|c|c|c|}
\hline Telemedicine setup & Dates with sentinel events & Changes made if any \\
\hline Business as usual & February 1-28 & News of COVID in Europe \\
\hline New patients seen in person & & Plans to expand telemedicine \\
\hline Telemedicine only for follow-up patients & & $\begin{array}{l}\text { All tech checks by the telemedicine } \\
\text { department }\end{array}$ \\
\hline $\begin{array}{l}\text { Tele-multidiscipline clinics in planning } \\
\text { stages }\end{array}$ & & Vidyo platform used \\
\hline \multicolumn{3}{|l|}{$\begin{array}{l}\text { Few home-based telemedicine clinics for } \\
\text { epilepsy and movement }\end{array}$} \\
\hline $\begin{array}{l}\text { Discussions with telemedicine } \\
\text { department to expand services }\end{array}$ & March 1-15: Shelter in place orders & Increased Vidyo licenses \\
\hline \multirow{2}{*}{$\begin{array}{l}\text { Triage list given to schedulers by } \\
\text { symptoms }\end{array}$} & & Started launch of Vidyo through EMR_Epic \\
\hline & & Patients access MyChart to access Vidyo \\
\hline $\begin{array}{l}\text { Telemedicine command center set up to } \\
\text { support telemedicine through the } \\
\text { hospital }\end{array}$ & $\begin{array}{l}\text { March 15-30: all in-person clinic visits changed } \\
\text { to home-based telemedicine visits (clinicians in } \\
\text { home office or private office with a camera) }\end{array}$ & Additional cameras ordered for telemedicine \\
\hline \multirow{2}{*}{$\begin{array}{l}\text { Lectures for faculty on implementing } \\
\text { telemedicine focusing on examination, } \\
\text { documentation, and billing }\end{array}$} & & Medical assistants to conduct tech checks \\
\hline & & $\begin{array}{l}\text { Teaching clinics not launched yet due to } \\
\text { limited Vidyo licenses }\end{array}$ \\
\hline \multirow{2}{*}{$\begin{array}{l}\text { Additional educational lecture to faculty } \\
\text { for navigating telemedicine from home } \\
\text { offices }\end{array}$} & March 30-April 30 & $\begin{array}{l}\text { Neurology nurses assume tech checks as } \\
\text { volumes increase }\end{array}$ \\
\hline & & Teaching and fellow clinics launched \\
\hline \multirow{2}{*}{$\begin{array}{l}\text { Clinicians now to review patient lists to } \\
\text { screen for appropriateness for } \\
\text { telemedicine vs in-person visits }\end{array}$} & May 11,2020 & $\begin{array}{l}\text { In-person clinics opened with limited visits } \\
\text { per day }\end{array}$ \\
\hline & & $\begin{array}{l}\text { Partnership with interpretation services for } \\
\text { non-English-speaking patients }\end{array}$ \\
\hline
\end{tabular}

Abbreviation: EMR = electronic medical record

unequal to an in-person visit. In addition, higher numbers of younger and medically complex patients were seen DSD. It will be interesting to determine whether these differences decrease over time as telemedicine use continues. In addition, the rate of counseling (discussion of treatment risks/benefits and anticipatory guidance) was significantly higher BSD than DSD. The reasons for this are not clear; however, it could reflect documentation style rather than true practice change during a stressful period or providers running short on time as they adapted to telemedicine.

Overall, a very low rate of in-person visits (2.3\%) within 30 days of telemedicine visit for the same symptom was found. Our rate is lower than the $5 \%$ recently quoted from a large cohort of home-based and telephone encounter visits. ${ }^{7}$ The nonzero rate of need for in-person care in that study and ours indicates that a practice model based on $100 \%$ telemedicine with no in-person appointment availability may result in fragmented or incomplete care for pediatric neurology patients.
The very low rates of hospitalization (1.4\%) and zero deaths after a telemedicine visit for this large cohort are reassuring when considering safety. In sum, these quality and safety measures indicate that telemedicine-based care was sufficient for the large majority of pediatric neurology patients. For those who did need further in-person evaluation or phone support, telemedicine facilitated triage and severe acute respiratory syndrome coronavirus 2 risk management strategies by determining who could wait for a routine in-person appointment.

There is a perception that telemedicine examination of the very young is limited compared with older children. We found that compared with the older cohort, younger patients were more likely to be new patient referrals, and therefore as expected with new patients, there was a significantly higher chance of newer diagnoses across various subspecialties and higher chance of receiving new medications. Not surprisingly, there was also higher chance of calls within 7 days, likely due to the need to explain new treatment or a plan. Looking 
at absolute numbers though, there were still very few families of young patients that called within 7 days of visit. Contrary to perception about infant and toddler examinations, these patients did have examination of additional systems documented. This most likely reflects the need for more comprehensive examinations in a subgroup with newer and less verbal patients. Another potential explanation is that a younger patient is less mobile therefore in view of the camera during a telemedicine visit, making it easier to examine patient. This is an important finding to note when deciding to implement telemedicine in new young patient visits.

We chose to further analyze patients with neuromuscular and epilepsy diagnoses due to the perception that sensorimotor system examination in telemedicine visits is challenging. ${ }^{13}$

When comparing this cohort with patients with epilepsy, vitals were less commonly documented. It is possible that patients with neuromuscular diagnoses are less mobile and therefore weighed less often at home than patients with epilepsy. It is important to note that the 2 groups were no different from each other with respect to number of systems examined. This could be looked at in 2 ways-an adequate examination can be performed through telemedicine for neuromuscular patients or more likely that the number of systems examined measure does not sufficiently evaluate the sensorimotor system examination for these patients. Because patients with epilepsy are more likely to receive changes with medication therapy during a visit, it is not surprising that they were more likely to call than patients in the neuromuscular group. The fact that there was no difference between the 2 groups with respect to hospitalization or the need to be seen in person within 30 days is another important finding when considering telemedicine for neuromuscular patients, who are more medically vulnerable and in greater need of social isolation during the pandemic. ${ }^{14}$

\section{Limitations}

This retrospective data review covered 1 geographic region and 1 pediatric tertiary care system. Our division was an early adopter of telemedicine even before COVID-19, which means that the data may not be applicable to inexperienced centers. The processes, technology, infrastructure, and support needed to make telemedicine a success are not uniform across institutions.

We missed encounters like clinical research encounters and those in certain complex multidisciplinary clinics (e.g., stroke clinic) based on our EMR search terms. However, these represent a small percentage of encounters in relation to the overall pediatric neurology practice, so any missed encounters would likely not affect our analysis in a significant manner.

There is also possibility of a selection bias by allowing physicians to determine up front which patients needed inperson care, skewing results toward lower-risk complaints.
This effect was not likely to be high-given that telemedicine encounters DSD reached $\geq 75 \%$ of the total usual in-person visits at peak use; it also underscores our conclusion that a high-quality and safe pediatric neurology telemedicine practice should include seamless access to in-person care for cases when exclusive telemedicine-based care is insufficient to meet a patient's needs.

Our results are robust and useful because all encounters were evaluated through manual chart review to evaluate characteristics and outcomes, which cannot be identified from demographic and coding data as was used in a different study. ${ }^{7}$ Furthermore, all reviewers used a consistent protocol to code various features of the home-based visit that was based on expected features of in-person visit, making the results relatable to usual practice.

Our study points out that although telemedicine is thought to eliminate socioeconomic barriers, when it comes to homebased telemedicine, there might still be barriers and inequality that becomes obvious due to the sheer numbers of encounters analyzed in this study.

Our study also focuses on certain subgroups of patients seen through telemedicine-the very young, patients with challenging examinations (patients with neuromuscular complaints) and new patient visits. We hope that our numbers contribute to the "need for more data" in the ongoing validation of telemedicine for different patient populations and serve as an example of how other centers may use metrics such as those created by SPROUT for national use during the COVID-19 pandemic to standardize research in telemedicine. ${ }^{6}$

In sum, telemedicine is a clinically useful, high-quality and safe option for the large majority of pediatric neurology patients based on an in-depth review of $>2,000$ patients. During pandemic operations, it is also useful even for those who need in-person evaluation by facilitating the determination of who can wait for a routine in-person appointment and who needs to be seen promptly.

\section{Acknowledgment}

EMR extraction was conducted with data services and consultation provided by Research Informatics in the Analytics Resource Center at Children's Hospital Colorado. The authors thank Drs. Abhay Divekar, MD, Kevin Chapman, MD, Elaine Wirrell, MD, and Kelly Knupp, MD, for careful reading and critique of the manuscript. They thank Briana Kille, $\mathrm{PhD}$, data analyst for the EMR extraction.

\section{Study Funding}

The statistician's time was funded by the epilepsy research fund at the Neurosciences Institute of Children's Hospital Colorado awarded to Dr. Joshi for this work. Dr. Olson's time is supported by NIH/NCATS SPROUT-CTSA Collaborative Telehealth Network Grant U01TR002626. 
TAKE-HOME POINTS

$\rightarrow$ Largest cohort of safety (death) and quality outcomes (telephone calls and hospital admission) of telemedicine visits in child neurology using SPROUT guidelines.

$\rightarrow$ Very low rates of cause specific readmissions to hospital after a telemedicine visit.

$\rightarrow$ Greater number of urban patients seen DSDhighlighting the health care disparities and digital divide brought forth during the pandemic.

$\rightarrow$ No difference in safety and quality outcomes when comparing very young patient/new vs follow-up visits.

$\rightarrow$ No difference in safety and quality outcomes when comparing patients with neuromuscular diagnosis with other (epilepsy) diagnosis.

\section{Disclosure}

The authors report no disclosures relevant to the manuscript. Full disclosure form information provided by the authors is available with the full text of this article at Neurology.org/cp.

\section{Publication History}

Received by Neurology: Clinical Practice July 28, 2020. Accepted in final form October 29, 2020.

\section{Appendix Authors}

\begin{tabular}{|c|c|c|}
\hline Name & Location & Contribution \\
\hline $\begin{array}{l}\text { Charuta N. Joshi, } \\
\text { MBBS }\end{array}$ & $\begin{array}{l}\text { University of Colorado } \\
\text { School of Medicine, } \\
\text { Anschutz Medical } \\
\text { Campus, Children's } \\
\text { Hospital Colorado, } \\
\text { Aurora }\end{array}$ & $\begin{array}{l}\text { Study concept, design, } \\
\text { acquisition of data, } \\
\text { analysis of data, } \\
\text { manuscript writing and } \\
\text { editing, and figure } \\
\text { editing. }\end{array}$ \\
\hline $\begin{array}{l}\text { Michele L. Yang, } \\
\text { MD }\end{array}$ & $\begin{array}{l}\text { University of Colorado } \\
\text { School of Medicine, } \\
\text { Anschutz Medical } \\
\text { Campus, Children's } \\
\text { Hospital Colorado, } \\
\text { Aurora }\end{array}$ & $\begin{array}{l}\text { Data acquisition, drafted } \\
\text { figure 1, and manuscript } \\
\text { editing }\end{array}$ \\
\hline $\begin{array}{l}\text { Krista Eschbach, } \\
\text { MD }\end{array}$ & $\begin{array}{l}\text { University of Colorado } \\
\text { School of Medicine, } \\
\text { Anschutz Medical } \\
\text { Campus, Children's } \\
\text { Hospital Colorado, } \\
\text { Aurora }\end{array}$ & $\begin{array}{l}\text { Data acquisition and } \\
\text { manuscript editing }\end{array}$ \\
\hline Suhong Tong, MS & $\begin{array}{l}\text { Children's Hospital } \\
\text { Colorado; Colorado } \\
\text { School of Public Health, } \\
\text { University of Colorado } \\
\text { School of Medicine, } \\
\text { Anschutz Medical } \\
\text { Campus, Aurora }\end{array}$ & $\begin{array}{l}\text { Statistical analysis and } \\
\text { manuscript editing }\end{array}$ \\
\hline
\end{tabular}

Appendix (continued)

\begin{tabular}{|c|c|c|}
\hline Name & Location & Contribution \\
\hline $\begin{array}{l}\text { Mona P. Jacobson, } \\
\text { MSN, CPNP }\end{array}$ & $\begin{array}{l}\text { University of Colorado } \\
\text { School of Medicine, } \\
\text { Anschutz Medical } \\
\text { Campus, Children's } \\
\text { Hospital Colorado, Aurora }\end{array}$ & $\begin{array}{l}\text { Data acquisition and } \\
\text { manuscript editing }\end{array}$ \\
\hline $\begin{array}{l}\text { Chelsey Stillman, } \\
\text { PA-C }\end{array}$ & $\begin{array}{l}\text { University of Colorado } \\
\text { School of Medicine, } \\
\text { Anschutz Medical } \\
\text { Campus, Children's } \\
\text { Hospital Colorado, Aurora }\end{array}$ & $\begin{array}{l}\text { Data acquisition and } \\
\text { manuscript editing }\end{array}$ \\
\hline $\begin{array}{l}\text { Annmarie E. Kropp, } \\
\text { DNP }\end{array}$ & $\begin{array}{l}\text { University of Colorado } \\
\text { School of Medicine, } \\
\text { Anschutz Medical } \\
\text { Campus, Children's } \\
\text { Hospital Colorado, Aurora }\end{array}$ & $\begin{array}{l}\text { Data acquisition and } \\
\text { manuscript editing }\end{array}$ \\
\hline $\begin{array}{l}\text { Stephanie A. Shea, } \\
\text { BS, MPAS, PA-C }\end{array}$ & $\begin{array}{l}\text { University of Colorado } \\
\text { School of Medicine, } \\
\text { Anschutz Medical } \\
\text { Campus, Children's } \\
\text { Hospital Colorado, Aurora }\end{array}$ & $\begin{array}{l}\text { Data acquisition and } \\
\text { manuscript editing }\end{array}$ \\
\hline $\begin{array}{l}\text { Gerard M. Frunzi, } \\
\text { MBA }\end{array}$ & $\begin{array}{l}\text { Children's Hospital } \\
\text { Colorado, Aurora }\end{array}$ & $\begin{array}{l}\text { Data acquisition and } \\
\text { manuscript editing }\end{array}$ \\
\hline $\begin{array}{l}\text { J. Fred Thomas, } \\
\text { PhD }\end{array}$ & $\begin{array}{l}\text { University of Colorado } \\
\text { School of Medicine, } \\
\text { Anschutz Medical } \\
\text { Campus, Children's } \\
\text { Hospital Colorado, } \\
\text { Aurora; Children's } \\
\text { Hospital Colorado, } \\
\text { Aurora }\end{array}$ & $\begin{array}{l}\text { Data acquisition and } \\
\text { manuscript editing }\end{array}$ \\
\hline $\begin{array}{l}\text { Christina A. Olson, } \\
\text { MD }\end{array}$ & $\begin{array}{l}\text { University of Colorado } \\
\text { School of Medicine, } \\
\text { Anschutz Medical } \\
\text { Campus, Children's } \\
\text { Hospital Colorado, Aurora; } \\
\text { Children's Hospital } \\
\text { Colorado, Aurora }\end{array}$ & $\begin{array}{l}\text { Study design, data } \\
\text { acquisition, and } \\
\text { manuscript editing }\end{array}$ \\
\hline
\end{tabular}

\section{References}

1. Lo MD, Gospe SM Jr. Telemedicine and child neurology. J Child Neurol 2019;34: $22-26$

2. Joshi C. Telemedicine in pediatric neurology. Pediatr Neurol 2014;51:189-191.

3. Olson CA, Thomas JF. Telehealth: no longer an idea for the future. Adv Pediatr 2017; 64:347-370.

4. Jury SC, Kornberg AJ. Integrating telehealth in to "business as usual": is it really possible? J Telemed Telecare 2016;22:499-503

5. Hatcher-Martin JM, Adams JL, Anderson ER, et al. Telemedicine in neurology: telemedicine work group of the American Academy of Neurology update. Neurology 2020;94:30-38

6. Chuo J, Macy ML, Lorch SA. Strategies for evaluating telehealth. Pediatrics 2020;146: e20201781.

7. Rametta SC, Fridinger SE, Gonzalez AK, et al. Analyzing 2,589 child neurology telehealth encounters necessitated by the COVID-19 pandemic. Neurology 2020;95: e1257-e1266.

8. Benda NC, Veinot TC, Sieck CJ, Ancker JS. Broadband internet access is a social determinant of health! Am J Public Health 2020;110:1123-1125.

9. Vazquez J, Islam T, Gursky J, Beller J, Correa DJ. Access to care matters: remote health care needs during COVID-19. Telemed J E Health Epub 2020 Sep 30.

10. American Academy of Neurology. Telemedicine and COVID-19. 2020. Available at: https://www.aan.com/tools-and-resources/covid-19-neurology-resource-center/. Accessed December 29, 2020.

11. Child Neurology Society. Resource tool kit for the child neurologist in the midst of the COVID-19 pandemic. 2020. Available at: Same issue as above: https://www.childneurologysociety.org/docs/default-source/2020-cns-/cns-toolkit-for-telemedicine(apr-5).pdf?sfursn=1a5065b8_2. Accessed December 29, 2020.

12. Saporta MA, Granit V, Lewis $\overline{\mathrm{R}}$, Benatar M. Yes, we can: neuromuscular examination by telemedicine. Muscle Nerve 2020;62:E83-E85.

13. Desai J, Vishwanath V. Deliberation is needed before advocating telemedicine for routine use in child neurology after the pandemic. Pediatr Neurol 2020;113:42.

14. Guidon AC, Amato AA. COVID-19 and neuromuscular disorders. Neurology 2020; 94:959-969. 


\title{
Neurology ${ }^{\circ}$ Clinical Practice
}

\author{
Quality and Safety Analysis of 2,999 Telemedicine Encounters During the COVID-19 \\ Pandemic \\ Charuta N. Joshi, Michele L. Yang, Krista Eschbach, et al. \\ Neurol Clin Pract 2021;11;e73-e82 Published Online before print December 3, 2020 \\ DOI 10.1212/CPJ.0000000000001025
}

This information is current as of December 3, 2020

$\begin{array}{ll}\begin{array}{l}\text { Updated Information \& } \\ \text { Services }\end{array} & \begin{array}{l}\text { including high resolution figures, can be found at: } \\ \text { http://cp.neurology.org/content/11/2/e73.full.html }\end{array} \\ \text { References } & \text { This article cites } 11 \text { articles, } 0 \text { of which you can access for free at: } \\ & \text { http://cp.neurology.org/content/11/2/e73.full.html\#\#ref-list-1 } \\ & \text { This article has been cited by } 2 \text { HighWire-hosted articles: } \\ & \text { http://cp.neurology.org/content/11/2/e73.full.html\#\#otherarticles } \\ \text { Citations } & \text { This article, along with others on similar topics, appears in the } \\ & \text { following collection(s): } \\ \text { All Pediatric } & \\ \text { http://cp.neurology.org//cgi/collection/all_pediatric } \\ \text { Cohort studies } \\ \text { http://cp.neurology.org//cgi/collection/cohort_studies } \\ \text { COVID-19 } \\ \text { http://cp.neurology.org//cgi/collection/covid_19 } \\ \text { Outcome research } \\ \text { http://cp.neurology.org//cgi/collection/outcome_research } \\ \text { Information about reproducing this article in parts (figures,tables) or in } \\ \text { its entirety can be found online at: } \\ \text { http://cp.neurology.org/misc/about.xhtml\#permissions } \\ \text { Information about ordering reprints can be found online: } \\ \text { http://cp.neurology.org/misc/addir.xhtml\#reprintsus }\end{array}$

Neurol Clin Pract is an official journal of the American Academy of Neurology. Published continuously since 2011, it is now a bimonthly with 6 issues per year. Copyright $\odot 2020$ American Academy of Neurology. All rights reserved. Print ISSN: 2163-0402. Online ISSN: 2163-0933.

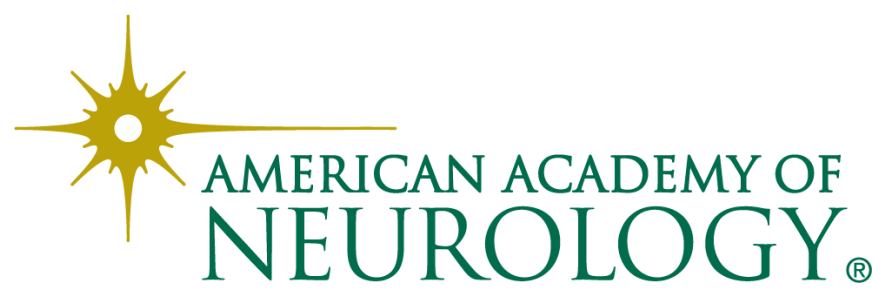

